\title{
CHANGES IN EVAPOTRANSPIRATION AND THE POTENTIAL DRIVERS IN ASIAN ARID REGIONS DURING 2003 TO 2017
}

\author{
Xingcai Liu, Qiuhong Tang \\ Key Laboratory of Water Cycle and Related Land Surface Processes, Institute of Geographic Sciences and Natural \\ Resources Research, Chinese Academy of Sciences, Beijing, China \\ Email: xingcailiu@igsnrr.ac.cn
}

\begin{abstract}
:
Evapotranspiration (ET) has changed greatly across the world in the past decades. There are various drivers that may affect the changes in ET. Understanding the changes in ET and the potential drivers is of great importance to water resources management in the arid regions. In this study, we examine the trends in ET using satellite-based data in the Asian arid regions from 2003 to 2017. Trends in different ET components, i.e., the evaporation from bare soil and transpiration from vegetation, are estimated to examine their respective contributions to the changes in ET. The results show that the evaporation from bare soil is the main component of ET and has contributed larger to the changes in ET from 2003 to 2017. Statistically significant increasing trend is mostly found in Southwest Pakistan, Northwest India, Southeast Iran, many areas in Northwest China, and some parts in South Kazakhstan. The relations between ET and the global sea surface temperature (SST) are also examined. It suggests that the interannual variation of ET is closely related to annual SST anomalies in most areas, especially in Kazakhstan, Turkmenistan, Northwest China, Southwest Pakistan, and some parts of eastern Iran. This analysis provides useful information for water resources management and planning with respect to forest and agricultural development in the Asian arid regions.
\end{abstract}

KEY WORDS: Evapotranspiration, Climate change, Hydrological change, SST, Arid regions

\section{INTRODUCTION}

Evapotranspiration (ET) is a key process among the landatmosphere interactions and is affected by the variability of various climate and hydrological variables. Decline trend in the land ET has been observed in many regions from both in-situ measurements and reanalysis dataset, which was due to limited soil moisture (Jung et al., 2010). However, ET might increase in some arid and semi-arid regions; a model-based analysis showed that the wind speed decline may result in less ET while larger wind speed could increase ET in China (Liu et al., 2014). Arid regions are often sensitive to environmental change and might expand under future climate change (Huang et al., 2016). So far, the changes in ET and the potential drivers are not well understood due to data unavailability in arid regions. Most studies focused on pan / reference evaporation (e.g., Shen et al., 2010; Shiri, 2017), while the changes of actual ET were seldom studied. The remote sensing data are increasingly used to estimate hydrological variables like ET (Fisher et al., 2008; Huang et al., 2017). The factors that locally connected to changes in ET varies over regions (Teuling et al., 2009). However, the teleconnection between changes in ET and large circulation indices are less investigated. The hydroclimatology in the Asian arid regions is important to the monsoon climate system. It would be of great interest to demonstrate the spatiotemporal evolution of changed and the potential drivers in arid regions. A better understanding of ET would significantly favour water resources management and forest management in arid regions (Attarod et al., 2018).

In this study, we attempt to examine the spatiotemporal changes in ET in the Asia arid regions by using a remote sensing-based ET dataset. The relations between changes in ET and SST are also explored. This paper is organized as the following, section 2 presents the method used in this study, section 3 shows the results, and section 4 summarize findings from the analysis and draw conclusions.

\section{METHOD}

We obtain the annual ET, evaporation from bare soil $(\mathrm{Eb})$, and transpiration (Ts) in the Asian arid region for the 20032017 period from the GLEAM dataset (Martens et al., 2017). The Asian arid regions are identified by using a small value (less than 0.2) of the aridity index (i.e., the ration of precipitation to potential ET). The linear trend in ET, Eb, and Ts are estimated by using a linear regression method. Sea surface temperature (SST) dataset from the Hadley Centre (HadSST3) () was used in this study.

Linear trend in ET is estimated from a linear regression by using the least square method:

$y=a x+b$.

The Pearson correlation coefficient is calculated as the follows:

$$
R_{x, y}=\frac{\sum_{i=1}^{n}\left(x_{i}-\bar{x}\right)\left(y_{i}-\bar{y}\right)}{\sqrt{\sum_{i=1}^{n}\left(x_{i}-\bar{x}\right)^{2}} \sqrt{\sum_{i=1}^{n}\left(y_{i}-\bar{y}\right)^{2}}} .
$$

The $95 \%$ significance level of linear trends and correlation coefficients are estimated with the Student $t$-test.

\section{RESULTS}

Figure 1 shows the multi-year mean annual ET and the trend in the annual ET over the Asian arid regions from 2003 to 2017. Annual ET is generally less than $200 \mathrm{~mm}$ and is less than $100 \mathrm{~mm}$ in many areas (Figure 1a). The annual ET is larger in western areas than that in eastern areas. It is also significantly related to climate conditions, that is, the wetter climate, the larger ET. The annual ET shows an increase trend in most areas (Figure 1b), especially in eastern areas (e.g. Northwest China). Statistically significant increasing trend is found in Southwest Pakistan, Northwest India, Southeast Iran, some areas in Kazakhstan, and many areas in Northwest China (see dotted area in Figure 1b). A decline but non-significant trend is mainly 
found in the areas around the Caspian Sea. The trend is less than $2 \mathrm{~mm} /$ year for most areas.

Figure 2 shows the multi-year mean annual $\mathrm{Eb}$ and $\mathrm{Ts}$, and the trends in annual $\mathrm{Eb}$ and $\mathrm{Ts}$ in the Asian arid regions from 2003 to 2017. The spatial pattern of annual evaporation from bare soil (Figure 2a) is very similar to the annual ET (see Figure 1a), which is less than $100 \mathrm{~mm}$ in many areas. The large $\mathrm{Eb}$ values mostly appear in Southwest Pakistan and Afghanistan, and Southeast Iran. The trend in annual Eb (Figure 2b) has similar spatial patterns with that of annual ET, but its magnitude is smaller (mostly less than $2 \mathrm{~mm} /$ year). However, the areas with statistically significant trends in $\mathrm{Eb}$ (dotted areas in Figure $2 \mathrm{~b}$ ) are generally the same as that of ET (see Figure 1b). These areas are mostly in Northwest China, Pakistan, Afghanistan and Iran.

The annual transpiration is much smaller than annual $\mathrm{Eb}$ and is less than $25 \mathrm{~mm}$ in many areas. The relatively larger transpiration values are mostly found in Southwest Pakistan, northern parts of Northwest China, and some areas in Kazakhstan. The spatial patterns of the trend in annual transpiration are also similar with that of annual ET. However, the trend in annual transpiration is less than $1 \mathrm{~mm} /$ year in most areas. This indicates that the evaporation from bare soil $(\mathrm{Eb})$ is the main component of ET, and the changes in Eb contributed mostly changes in ET in the Asian arid regions from 2003 to 2017.
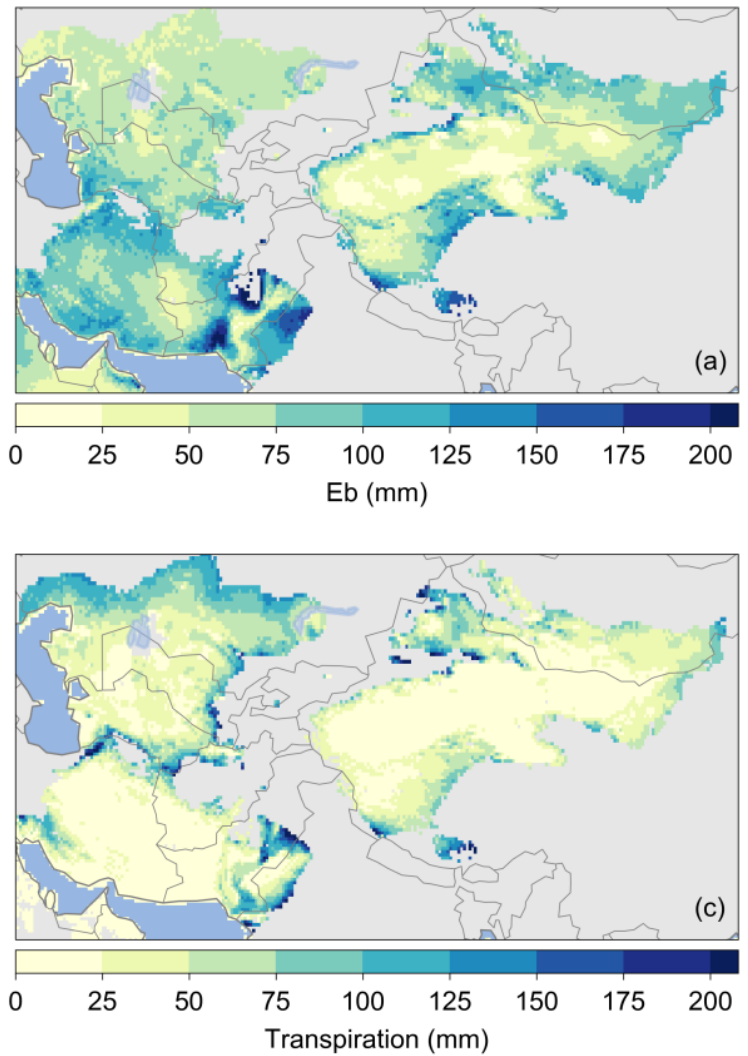
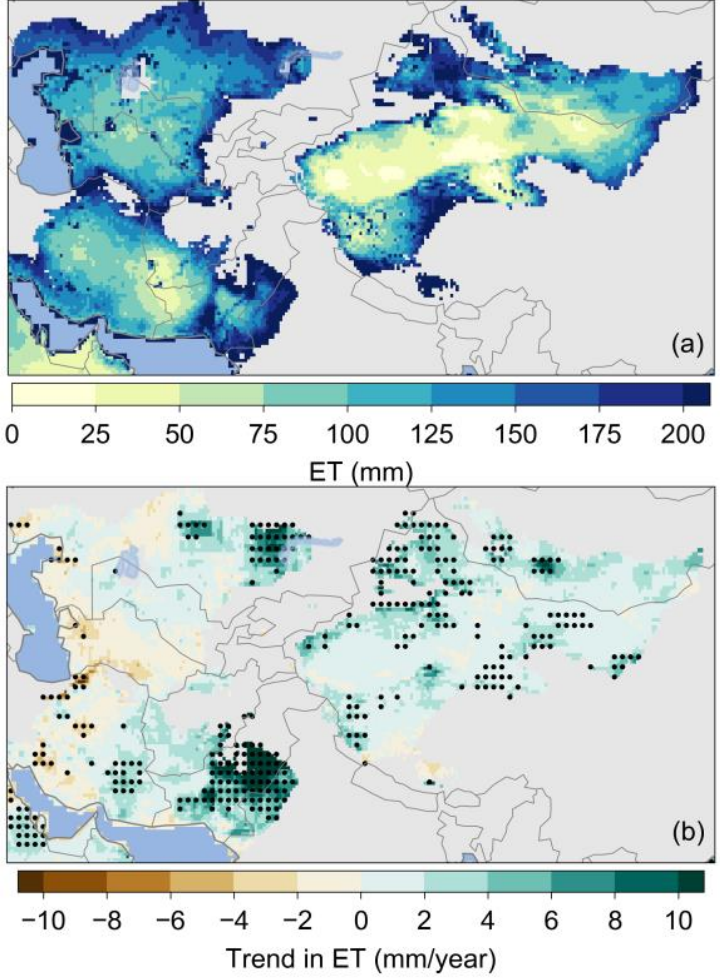

Figure 1. Multi-year mean annual evapotranspiration (ET) and the trend in annual ET from 2003 to 2017. The dotted areas indicate a statistically significant trend.
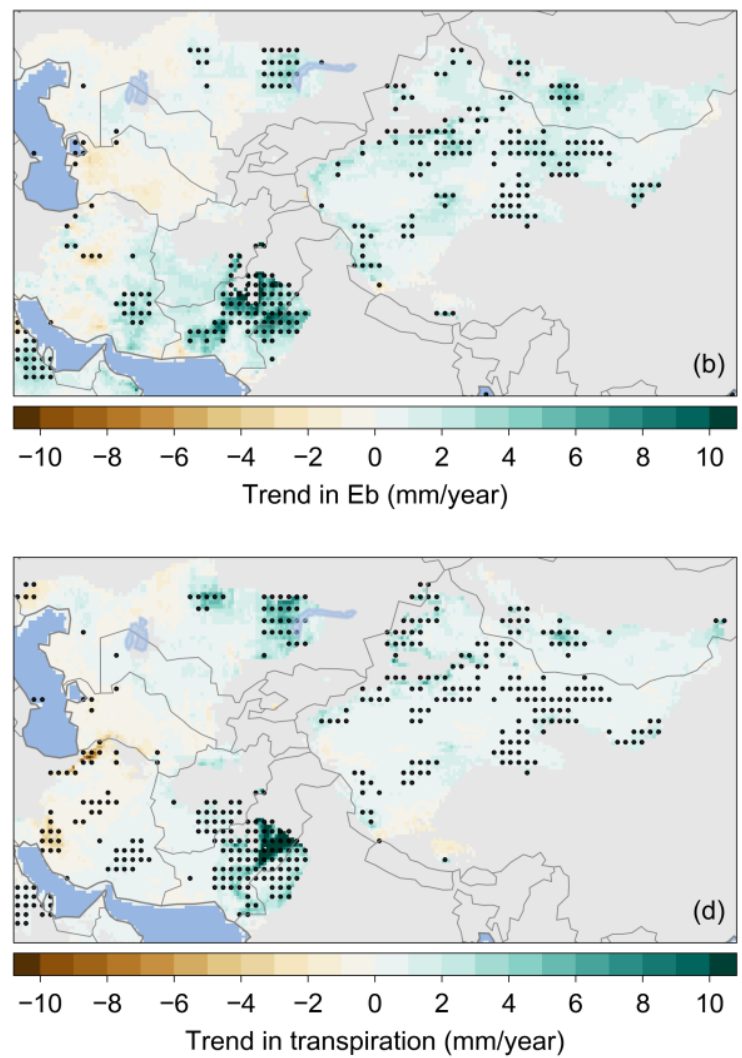

Figure 2. Multi-year mean annual evaporation from bare soil $(\mathrm{Eb})$ and transpiration (Ts), and the trend in annual Eb and Ts from 2003 to 2017. 
Figure 3 shows the correlations between ET in the Asian arid regions and global SST anomalies during the 2003-2017 period. The annual ET is positively related to global SST in most areas (Figure 3a). Statistically significant correlations (see dotted areas in Figure 3) are mostly found in northern Kazakhstan, large parts of Northwest China, Northwest Turkmenistan, Southwest Pakistan and eastern parts of Iran. This indicates that the SST variation could be a key driver of the interannual variation of ET in these areas. The relations between Eb (Figure 3b), transpiration (Figure 3c) and SST are generally the same as ET. It suggests that the evaporation from soil and transpiration of vegetation has similar response to SST changes.
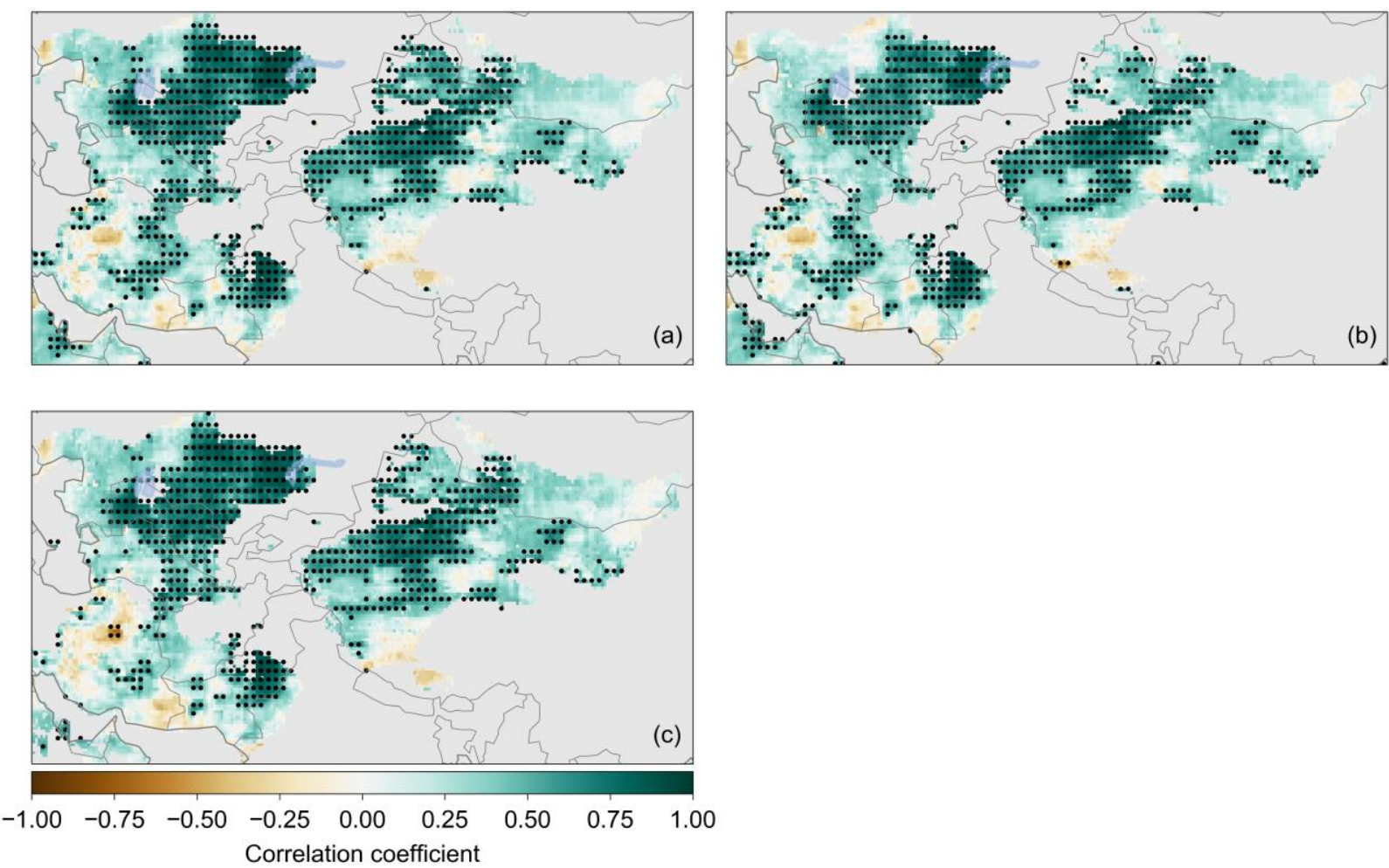

Figure 3. Correlation coefficients between ET in the Asian arid regions and global SST anomalies during the 2003-2017 period. (a): total ET, (b): evaporation from bare soil (Eb), (c): transpiration.

\section{CONCLUSIONS}

A satellite-based dataset shows that the ET has increased in most areas of the Asian arid regions from 2003 to 2017. Statistically significant increase trend is mostly found in Southwest Pakistan, Northwest India, Southeast Iran, many areas in Northwest China, and some parts in South Kazakhstan. In these arid regions, evaporation from bare soil is the main component of ET, and the changes in the evaporation from bare soil contributed to most changes in ET. The annual ET variations are significantly related to global SST anomalies in many areas, especially in Kazakhstan, Turkmenistan, Northwest China, Southwest Pakistan, and some parts of eastern Iran. Further studies are needed to understand how the climatic and hydrological variables influence the change in ET in the Asian arid regions.

\section{REFERENCES}

Attarod, P., Q. Tang, J. Van Stan Ii, and X. Liu (2018), National assessment of throughfall sensitivity to changes in storm magnitude for the forests of Iran, Forest Systems, 27(3), e019, doi: 10.5424/fs/2018273-13857.
Jung, M., et al. (2010), Recent decline in the global land evapotranspiration trend due to limited moisture supply, Nature, 467(7318), 951-954, doi: 10.1038/nature09396.

Huang, J., H. Yu, X. Guan, G. Wang, and R. Guo (2016), Accelerated dryland expansion under climate change, Nature Clim. Change, 6(2), 166-171, doi: 10.1038/nclimate2837.

Fisher, J. B., K. P. Tu, and D. D. Baldocchi (2008), Global estimates of the land-atmosphere water flux based on monthly AVHRR and ISLSCP-II data, validated at 16 FLUXNET sites, Remote Sens. Environ., 112(3), 901-919, doi: 10.1016/j.rse.2007.06.025.

Huang, L., Z. Li, Q. Tang, X. Zhang, X. Liu, and H. Cui (2017), Evaluation of satellite-based evapotranspiration estimates in China, J. Appl. Remote Sens., 11, doi: Artn 026019 10.1117/1.Jrs.11.026019.

Liu, X., X. Zhang, Q. Tang, and X. Zhang (2014), Effects of surface wind speed decline on modeled hydrological conditions in China, Hydrol. Earth Syst. Sci., 18(8), 2803-2813, doi: 10.5194/hess-18-2803-2014.

Martens, B., D. G. Miralles, H. Lievens, R. van der Schalie, R. A. M. de Jeu, D. Fernández-Prieto, H. E. Beck, W. A. Dorigo, and N. E. C. Verhoest (2017), GLEAM v3: satellite-based land evaporation and root-zone soil moisture, Geosci. Model Dev., 10(5), 1903-1925, doi: 10.5194/gmd-10-1903-2017.

Shen, Y., C. Liu, M. Liu, Y. Zeng, and C. Tian (2010), Change in pan evaporation over the past 50 years in the arid region of 
China, Hydrol. Processes, 24(2), 225-231, doi: 10.1002/hyp.7435.

Shiri, J. (2017), Evaluation of FAO56-PM, empirical, semiempirical and gene expression programming approaches for estimating daily reference evapotranspiration in hyper-arid regions of Iran, Agri. Wat. Manage., 188, 101-114, doi: 10.1016/j.agwat.2017.04.009.

Teuling, A. J., et al. (2009), A regional perspective on trends in continental evaporation, Geophys. Res. Lett., 36(2), doi: $10.1029 / 2008 \mathrm{gl} 036584$. 